\title{
Energy Consumption of Self-Compacting Concrete during Mixing and Its Impact on the Yield Stress Measured in the Ready-Mix Concrete Plant
}

\author{
V. Arularasi $\mathbb{D}^{1},{ }^{1}$ P. Thamilselvi $\mathbb{D}^{1},{ }^{1}$ Siva Avudaiappan $\mathbb{D D}^{2},{ }^{2}$ and Erick I. Saavedra Flores ${ }^{2}$ \\ ${ }^{1}$ Division of Structural Engineering, Department of Civil Engineering, College of Engineering Guindy, Anna University, \\ Chennai, India \\ ${ }^{2}$ Departamento de Ingeniería en Obras Civiles, Universidad de Santiago de Chile, Av. Ecuador 3659, Estación Central, Chile
}

Correspondence should be addressed to V. Arularasi; varularasi@gmail.com

Received 22 November 2020; Revised 25 February 2021; Accepted 3 March 2021; Published 27 March 2021

Academic Editor: Valeria Vignali

Copyright (C) 2021 V. Arularasi et al. This is an open access article distributed under the Creative Commons Attribution License, which permits unrestricted use, distribution, and reproduction in any medium, provided the original work is properly cited.

To find the energy required during the mixing process of self-compacting concrete in a ready-mixed concrete plant and correlate the results with the yield stress of concrete. Power consumption required during the mixing of concrete is measured with a wattmeter connected to the mixing unit's power supply. A coaxial cylinder viscometer is used to measure the yield stress of concrete. The clamp meter measures the power when the impeller rotates inside the coaxial cylinder viscometer, which is filled with concrete. When the impeller rotates in a coaxial cylinder filled with concrete, the power is measured by a clamp meter. Torque is obtained through the power relationship, which is an essential factor in determining the yield stress. The cost of a rheometer is so high that all construction industries, research institutions, and researchers cannot measure rheological parameters. Nowadays, all rheometers are automated; hence, the cost is very high. Tattersall's approach of power requirement in mixing the concrete and calculating the yield stress reduces the complexity in determining the rheological parameter.

\section{Introduction}

Concrete is a universal material widely used in the construction industry. Due to urban development, the use of concrete has been increasing significantly over the last few years. The performance of concrete is an essential factor for the smooth completion of the project. The cost of making concrete is an important consideration for all concrete manufacturers. Resource optimization is the best cost-saving method followed by most manufacturers [1]. Energy research is normally conducted in all of the manufacturing industries to optimize the use of resources. Priority should be given to the energy required to mix concrete in a readymix concrete (RMC) plant to minimize energy consumption in concrete production. Moreover, the development of infrastructure has led to an increase in the production of RMC plants. The introduction of new materials into concrete may increase energy consumption during the mixing process and affect the output during the concrete pouring and pumping process [2-4]. Therefore, it is necessary to determine the energy consumption and yield stress required by the concrete during the mixing process to have a proper understanding of the following aspects: how admixture dosage is used to optimize the energy required during the mixing process, reduction of yield stress, optimization of mixing times, flow characteristics, the yield stress obtained during concrete pouring, and also early completion of concrete placing activities. The mixing kinematics can be well understood with the help of the power required in concrete mixing [5-7]. The primary purpose is to find the effect of energy consumption on the yield stress of concrete during mixing. A flow test was also performed to find the impact on energy consumption and yield stress. Furthermore, the purpose of this investigation is to find the cause for the increase in power consumption and its effect on yield stress. Fly ash and GGBS (ground granulated blast-furnace slag) are 
two admixtures used in different proportions to find the energy consumption and yield stress of concrete. The yield stress is determined using a coaxial viscometer. Newtonian and non-Newtonian fluids are used to find calibration constant $K$ and $G$ of the coaxial viscometer. The yield stress $\left(\tau_{0}\right)$ for different grades of concrete such as M25, M30, and M40 with various $w / p$ ratios are determined, and the results are found analytically without using an automated system in the coaxial viscometer.

\subsection{Role of the Power Consumption Curve in Ready Mix} Concrete Manufacturing. The power consumption curve obtained during the mixing process is the only tool to control the uniformity of the concrete during the manufacturing process. In ready-mixed concrete, the power consumption curve plays a vital role because it is impossible to visually observe the concrete's uniformity when mixing is conducted in a closed chamber [8], as shown in Figure 1. During the mixing process, the power consumption value increases due to the torque resistance caused by the material in the mixing drum. Torque resistance and power consumption will change, while loading the material in the mixer drum during the mixing process [9]. Monitoring power consumption during mixing is a simple method to check the homogeneity of concrete [10]. The addition of new material may change the mixing time and delay the attainment of concrete homogeneity. Therefore, the study on material characteristics will give a clear understanding of power consumption curves, attain homogeneity, and fix the mixing time of different concrete types.

\subsection{Energy Consumption during the Mixing of Concrete in This} Project. The concrete is manufactured in the RMC plant in many ways, such as thoroughly mixed state and partially mixed concrete, that is, the fully mixed concrete is carried at the plant, and in other cases, partial mixing is done at the plant, while the remaining mix is processed in the truck mixer. In some other cases like batched concrete, the batching alone is executed at the plant, and the entire mixing is done in a truck mixer [11]. In this investigation, the entire mixing is processed at the plant, for which the power consumption required during mixing is determined using a wattmeter. The concrete ingredients are loaded from the top of the drum by a conveyor (Figure 2). Cement, fly ash, GGBS, and aggregates are stored in a silo, and through the pipeline, the materials are discharged into the mixer drum. As the ingredients are loaded, the mixer to overcome the torque consumes excess power, which leads to an increase in power consumption. Initially, the coarse aggregate loading starts followed by fine aggregate and mineral admixtures, finally cement with water and superplasticizer $[12,13]$. Each ingredient is loaded at 5 to 10 -second interval, which leads to an increase in power consumption gradually [13]. Initially, the power consumption will be at the lower level and peaks when the final discharge of water has taken place. These water droplets form a liquid bridge between the particles and consume peak power at this stage [14]. Then, the peak value decreases gradually when the homogeneity is obtained [15].
The power consumption will vary for different types of concrete, which comprise different compositions. This variation in power consumption depends on the characteristics of the material, such as shape, size, moisture, and absorption. All these factors determine how the materials react in the drum during the mixing operation. It depends on the attraction and repulsion between particles. Changes in mixing time will also increase power consumption. After the invention of high-performance concrete and self-compacting concrete, all concrete mixtures' mixing duration has changed to achieve homogeneity $[8,12,13,16]$. Some admixtures make the concrete mix more quickly and cause minimum power consumption compared with concrete consisting of rough-textured mineral admixtures [17]. For this reason, the study of characteristics of the new material in the manufacturing industry has been given prime importance. Introducing new admixtures makes the concrete mix for a longer duration so it can eliminate inhomogeneity in the concrete mixture [18-20].

\section{Properties of the Fresh Concrete}

Workability is an essential factor that must be maintained throughout the concrete placing process. ACI defines workability as the ease of use so that it can be easily mixed, placed, consolidated, and finished to a homogenous condition. The flow properties of concrete play another critical role in the concrete manufacturing industry, such as RMC plants. The concrete is pumped directly into the structure from the transit mixer. The structure constructed with the help of these materials plays a vital role in ensuring safety and durability. The flow characteristics of concrete are called concrete rheology [21]. Fresh concrete can cast the mixture into any desired shape. The hardened concrete should meet the standards in terms of shape, smoothness, strength, durability, shrinkage, and creep, and the cost should be as low as possible [22]. Due to the rheology of concrete, the shape and size of the building are appropriate, and the concrete mixture can be passed through the formwork to reach the required size. A good concrete flow can better complete the formwork without honeycombs and pores [23]. In recent days, the pumping of concrete needs excellent workability and flowability. The concrete will spread into the structural forms to fulfill the required shape and size of the structure. Hence, rheology is given prime importance in the current scenario [24]. The rheology of concrete is mainly determined by two parameters: yield stress and plastic viscosity. In general, these two parameters give a clear understanding of the flow characteristics of fresh concrete. Therefore, rheology is the scientific way to measure the workability of concrete [21].

2.1. Need for Rheological Studies. The flow of matter and the deformation of particles are called rheology, which deals with the relationship between stress, strain, strain rate, and time [21, 23]. The rheology of concrete has played a vital role in recent decades and has increased with the advent of self-compacting concrete (SCC) and RMC concrete. In 


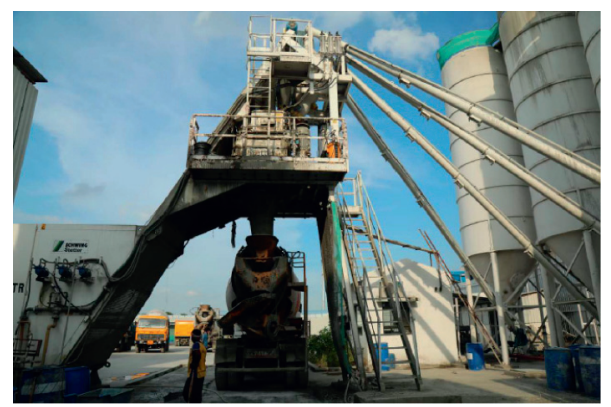

(a)

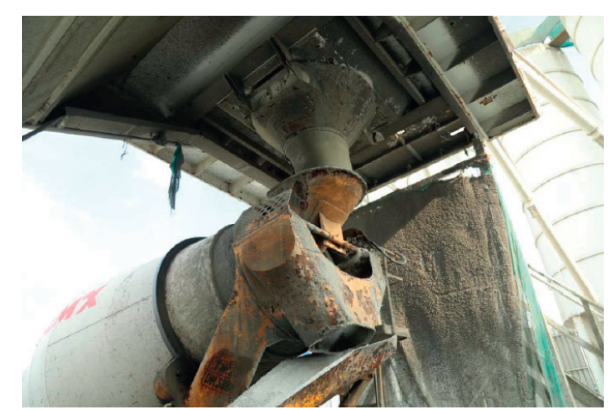

(b)

FIgure 1: (a) Mixing unit in the RMC plant. (b) Discharge of concrete from the mixer to the truck.

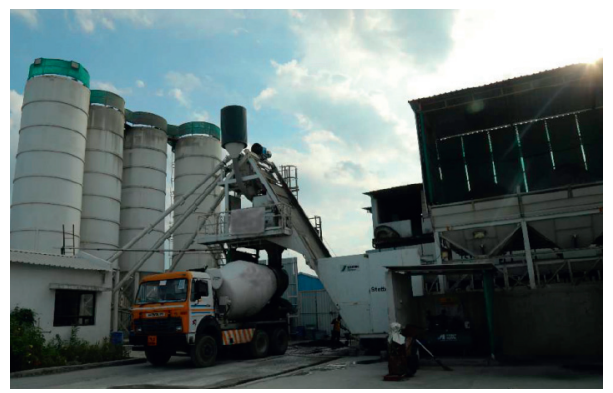

(a)

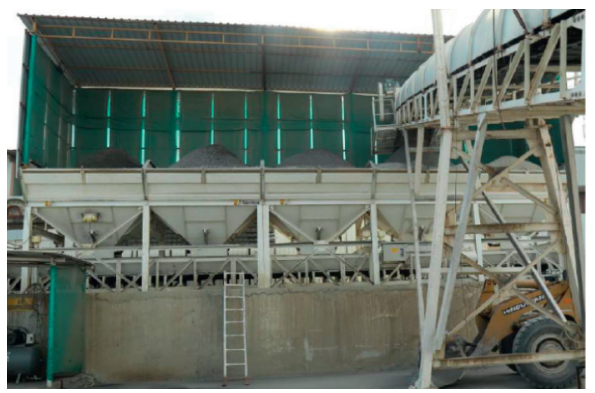

(b)

Figure 2: (a) Discharge of aggregate from the conveyor to the mixing chamber. (b) Aggregate stored in the storage bin.

SCC and RMC, the flow characteristics are essential for the easy conveying of concrete. The fluidity of concrete mainly depends on the effective water content. This is the difference between the total water required to mix the concrete and the water absorbed by the aggregate [13]. Recently, the SCC production has increased in highly reinforcement congested areas where the flow property is much concentrated to finish the formwork. The rheology of concrete has received attention because it greatly influences the hardened state of concrete [13, 21]. After the setting occurs, cement concrete will develop strength and stiffness and can withstand without support. This involves solid-like behavior, explained by the Bingham model, as shown in Figure 3. The Bingham model equation is given by $t=\tau_{0}+\mu$ $\dot{\gamma}$, where $t=$ shear stress, $\mu=$ plastic viscosity, $\dot{\gamma}=$ shear rate, and $\tau_{0}=$ yield stress.

This simple equation is used to determine the rheological behavior of the concrete. Concrete is a non-Newtonian fluid whose flow behavior is directly measured using this simple equation. In the Bingham equation, the shear stress and shear rate are a straight line where yield stress $\left(\tau_{0}\right)$ is an intercept on the $x$-axis and the slope is plastic viscosity $(\mu)$. For complex behavior, e.g., for special concrete, the Herschel and Bulkley equation is used. There are various empirical models used to fit the flow curve measurement. (i) Power law model, (ii) Bingham model, (iii) Herschel-Bulkley model, and (iv) Casson model. The power law model is expressed as $t=k \gamma$, where $k$ is the consistency coefficient. The value of $k$ is obtained by

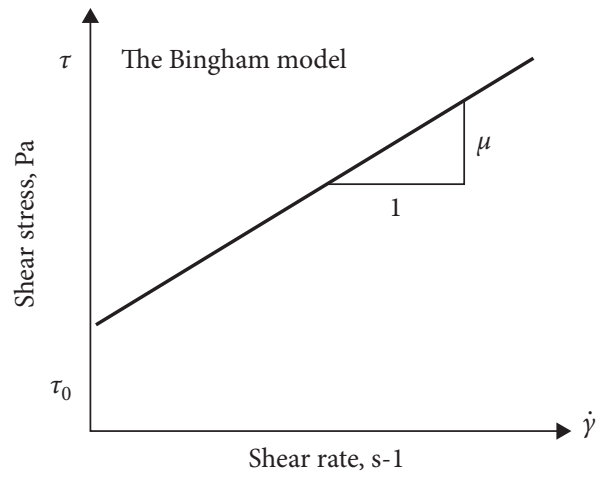

Figure 3: The Bingham model.

plotting a logarithmic graph between $t$ and $\gamma$ [25]. The Bingham model and the Herschel-Bulkley model are widely used to determine the rheological parameters $[26,27]$. In the Herschel-Bulkley model, $\tau=\tau_{0}+k \gamma^{n}$, where the parameters $\tau_{0}$ and $k$ correspond to the yield stress and consistency, respectively, and $n$ is the power index introduced for shear-thinning behavior, where it is less than 1 for shear-thinning behavior and greater than 1 for shearthickening behavior. When the index $n$ is equal to 1 , the Herschel-Bulkley model leads to the Bingham model, where $k$ represents plastic viscosity. Here, nonlinear regression analysis is used to determine rheological parameters [28, 29]. Another equation similar to the Bingham model is the Casson model. It is very similar to the 
Bingham equation, which is raised to a power of 0.5. Compared with the Bingham model, it is suitable for other materials and provides better results [30]. The Casson equation is given by $\tau^{1 / 2}=\tau_{0}^{1 / 2}+\mu^{1 / 2} \dot{\gamma}^{1 / 2}$ where $t$-shear stress, $\tau_{0}$-yield stress, $\mu$-plastic viscosity, and $\dot{\gamma}$-shear rate.

2.2. The Bingham Model vs. Power Equation. It has been established that fresh concrete, mortar, and cement paste are closely related to the Bingham model. The Bingham equation is the relationship between the stress we applied $(\tau)$ and the strain we obtained $(\dot{\gamma})$, which is very close to being linear, and it always has a positive intercept on the stress axis. The Bingham model equation is $t=\tau_{0}+\mu \dot{\gamma}$ [24]. The flow of concrete is very complex to measure the yield stress and plastic viscosity. According to Metzner-Otto, the power required by the coaxial viscometer during mixing, using known properties of the fluid, gives the value of yield stress and plastic viscosity. Here, the power equation is related to the Bingham equation to determine yield stress and plastic viscosity. The power equation $T=g+h \mathrm{~N}$ is similar to the Bingham equation $t=\tau_{0}+\mu \dot{\gamma}$. The " $g$ " and " $h$ " value from the power equation is similar to " $\tau_{0}$ " and " $\mu$ " values from the Bingham equation. Hence, less complication is involved in determining the yield stress and plastic viscosity by comparing the Bingham equation with the power equation.

2.3. Concrete Rheometers. There are different types of concrete rheometers available for the rheological study which is used around the world.

(i) BML viscometer $[23,31]$

(ii) BTRHEOM parallel-plate rheometer [23, 32, 33]

(iii) CEMAGREF-IMG coaxial rheometer [34]

(iv) IBB rheometer [23]

(v) Two-point workability apparatus [35]

For this research, a two-point workability apparatus is used, and an updated version of the rheometer is developed by Tattersall and Bloomer [35]. It is developed for concrete with a slump value higher than 100 . There are two impeller systems, helical and $H$-shaped. The helical impeller is used in concrete for workability ranges from medium to high. In this study, an $H$-shaped impeller is more effective for the workability range from low to medium. The flow of the concrete is too complex to measure the yield stress. Here, the torque is calculated from the power equation. The relationship between torque and speed is given by the power equation, $T=g+h \mathrm{~N}$. The measured data is then plotted against speed to get the rheological parameters.

\section{Methodology}

The RMC plant produces various grades of SCC. The power consumption of different concrete mixtures during mixing is measured in this study. A 100 amps wattmeter has been connected to the mixer. The power value is recorded for every second. The total power consumption obtained is related to the yield stress of concrete. Rheological parameters can be measured with a rheometer's aid and should be simple, durable, and suitable for various conditions. M25, M30, and M40 are the different concrete grades used here, and a coaxial cylindrical viscometer is used to determine the yield stress. The following steps are adopted, as shown in Figure 4 . The flow chart represents the method to determine the yield stress of the concrete and power consumption during mixing.

\section{The Coaxial Cylinder Viscometer}

For this study, Tattersall's two-point workability apparatus is used to measure the yield stress of the concrete. Several attempts have been made in the coaxial viscometer to determine the flow characteristics, workability measurement, and power requirement in mixing the fresh concrete [21]. The power measurement determines the mixing evolution of the concrete. The viscometer consists of a cylindrical drum with a volume of $25 \mathrm{~L}$. This drum is operated with a choice of gear. The hook provided makes the drum to rotate at different speeds at $0.06 \mathrm{rev} / \mathrm{sec}, 0.43 \mathrm{rev} / \mathrm{sec}, 0.608 \mathrm{rev} / \mathrm{sec}$, $1.09 \mathrm{rev} / \mathrm{sec}$, and $1.43 \mathrm{rev} / \mathrm{sec}$. The electrical power input is measured by a clamp meter (electrical device). It measures the power in two conditions, i.e., when the drum is filled with concrete and empty conditions as $P_{2}$ and $P_{1}$, respectively. The difference between these two powers $P_{1}$ and $P_{2}$, divided by the speed, will give the torque [22]. The impeller is mounted above the cylinder. The inspected material is kept inside the cylinder and made to rotate the impeller, and the power consumption is measured. This type is used because of the simplicity of measuring the torque and its robustness. The clamp meter is mounted on the input line of a coaxial cylindrical viscometer measures voltage $(V)$ and current $(I)$. The power $(P)$ is calculated by $P=V I$.

4.1. Calibration of the Coaxial Viscometer. The coaxial viscometer is calibrated to reduce empiricism and to obtain the value independent of the method of measurement $[21,36]$. The calibration is done by Newtonian and non-Newtonian fluids whose viscosity is determined by a commercially used viscometer called the redwood viscometer. An experimental investigation is carried out from the determination of viscosity of the Newtonian and non-Newtonian fluid, and hence, it is used to calibrate the coaxial viscometer to determine the calibration constant $K$ and $G$. The heavy gear oil is used for the Newtonian fluid, and for the non-Newtonian, a drilling fluid is used. The gear oil viscosity is higher than the viscosity of the drilling fluid. During calibration, it is necessary to equalize the Newtonian and non-Newtonian fluid viscosity by diluting with diesel. So, the gear oil is diluted with diesel to match the viscosity of the drilling fluid. Hence, the impeller rotated at the speed $N$ in the Newtonian material will be equivalent to the viscosity of the nonNewtonian fluid.

(i) The viscosity of the Newtonian fluid is obtained as 1253 centistoke $(\mathrm{cSt})$ (Table 1$)$

(ii) The viscosity of the non-Newtonian fluid is obtained as $35.11 \mathrm{cSt}$ (Table 2) 


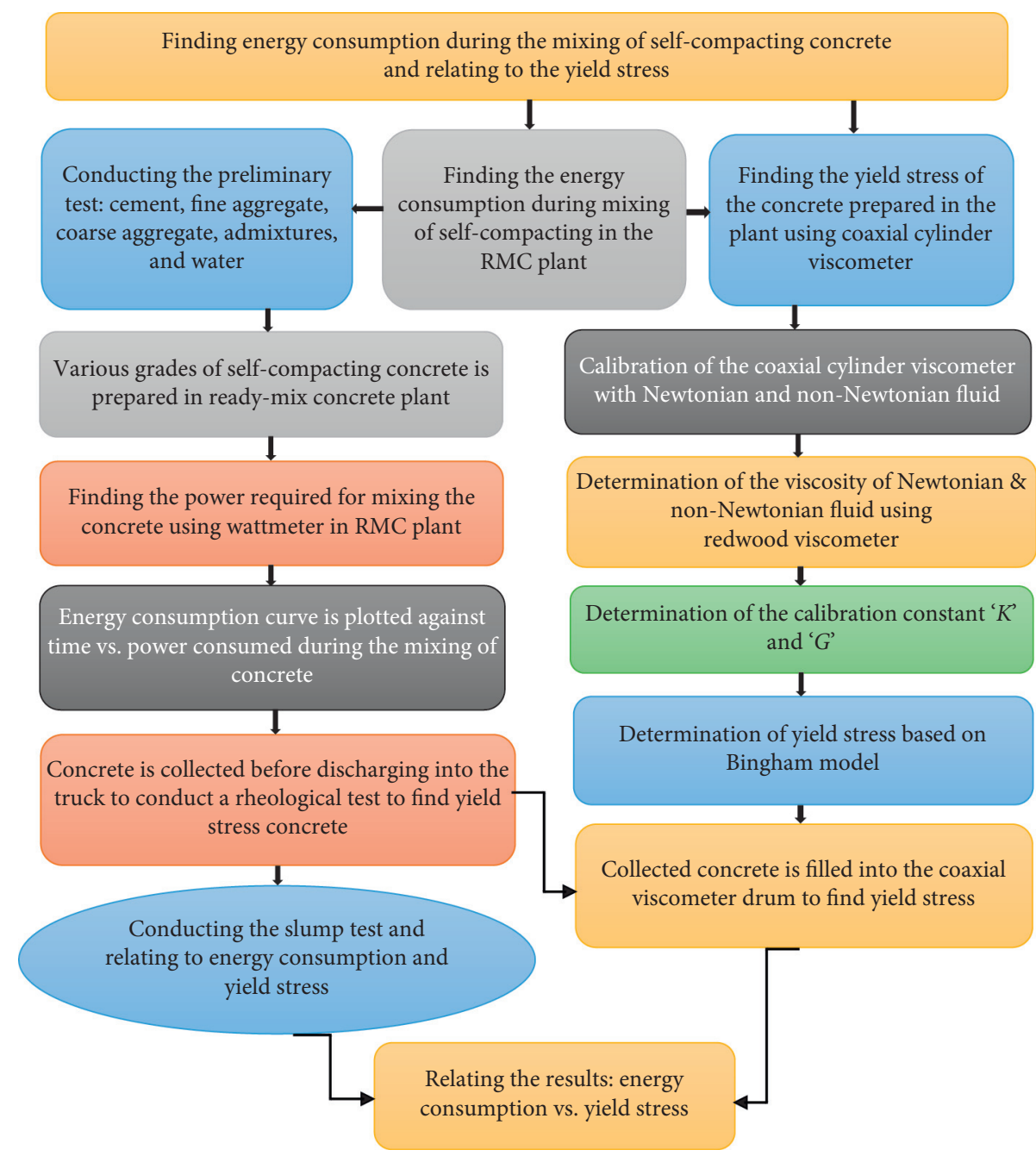

FIGURE 4: Methodology to determine energy consumption during mixing of concrete and its yield stress.

TABle 1: Viscosity of the Newtonian fluid.

\begin{tabular}{lccccc}
\hline $\begin{array}{l}\text { S. } \\
\text { no. }\end{array}$ & Temperature & $\begin{array}{c}\text { Time for } 50 \mathrm{cc} \text { oil flow } \\
(\mathrm{sec})\end{array}$ & $A$ & $B$ & $V(\mathrm{cSt})$ \\
\hline 1 & 34 & 466 & 2.7 & 2000 & 1253.90 \\
\hline
\end{tabular}

The apparent viscosity is calculated as viscosity $\mathrm{V}=A * t-B / t$ (centistokes). For any value, $A=2.7$ and $B=2000$. Hence, viscosity of the Newtonian fluid $=1253$ centistokes $(\mathrm{cSt})$.

TABLE 2: Viscosity of the non-Newtonian fluid.

\begin{tabular}{lccccc}
\hline $\begin{array}{l}\text { S. } \\
\text { no. }\end{array}$ & Temperature & $\begin{array}{c}\text { Time for 50 cc oil flow } \\
(\mathrm{sec})\end{array}$ & $A$ & $B$ & $V(\mathrm{cSt})$ \\
\hline 1 & 34 & 144 & 0.247 & 65 & 35.11 \\
\hline
\end{tabular}

Viscosity $v=A * t-B / t$, where $t=$ time for $50 \mathrm{cc}$ oil flow of oil in seconds and $A$ and $B=$ constants of the redwood viscometer varying with time. If $t=40$ to $80 \mathrm{sec}, A=0.264$ and $B=190$. If $t=85$ to $200 \mathrm{sec}, A=0.247$ and $B=65$. Therefore, viscosity $v=0.247 \times 146-65 / 146=1258.2-2000 /$ $466=35.11 \mathrm{cSt}$.

From Tables 1 and 2, it is observed that the viscosity of the Newtonian fluid does not match with the non-Newtonian fluid. Hence, the heavy gear oil is diluted with diesel to match gear oil viscosity with the drilling fluid [21]. Several combinations of diesel and gear oil are taken to match the viscosity with the drilling fluid. Finally, the combination of $100 \mathrm{ml}$ of gear oil with $50 \mathrm{ml}$ of diesel has matched the viscosity of the drilling, as shown in Table 3.

4.2. Redwood Viscometer. Redwood viscometer is a commonly used viscometer to determine the viscosity of the fluid. It consists of a capillary diameter of $3.5 \mathrm{~mm}$, length of $5 \mathrm{~mm}$, and a cup with a pointer. The constant head of oil and an agate jet is closed with the help of the ball. The ball is lifted to allow the flow of oil, and the oil is collected with the help of the container. The flow of oil in the container is measured. The jacket is provided for maintaining the oil at a constant temperature, and it is electrically heated. The uniform level of temperature is maintained by rotating the stirrer. A wire stirrer is also provided for pricing the oil samples. The viscosity of heavy gear oil and drilling fluid is determined using a redwood viscometer and is mentioned in Tables 1 and 2 .

4.3. Test Method of the Redwood Viscometer. The gear oil is filled in the redwood viscometer's vertical chamber to 
TABLE 3: Viscosity of heavy gear oil dilution.

\begin{tabular}{|c|c|c|c|c|c|c|c|}
\hline \multirow{2}{*}{ S. no. } & \multirow{2}{*}{ Temperature } & \multicolumn{2}{|c|}{ Quantity $(\mathrm{ml})$} & \multirow{2}{*}{ Time of $50 \mathrm{cc}$ oil flow (sec) } & \multirow{2}{*}{$A$} & \multirow{2}{*}{$B$} & \multirow{2}{*}{$V(\mathrm{cSt})$} \\
\hline & & Heavy gear oil & Diesel & & & & \\
\hline 1 & 34 & 20 & 200 & 30 & 0.247 & 65 & 5.243 \\
\hline 2 & 34 & 40 & 200 & 34 & 0.247 & 65 & 6.482 \\
\hline 3 & 34 & 90 & 200 & 36 & 0.247 & 65 & 7.086 \\
\hline 4 & 34 & 100 & 50 & 148 & 0.247 & 65 & 35.11 \\
\hline 5 & 34 & 100 & 50 & 144 & 0.247 & 65 & 35.11 \\
\hline
\end{tabular}

determine its viscosity. The cylinder is covered with a constant temperature bath and a capillary tube. The viscosity of the gear oil is measured by removing the stopper from the tube. Now, the Saybolt second is measured, i.e., the time taken for $60 \mathrm{ml}$ of oil to flow into the bottom of the container.

4.4. Determination of the Calibration Constant ( $K$ and $G$ ) Using the Non-Newtonian Fluid and Newtonian Fluid. The calibration constants $K$ and $G$ are found out by using non-Newtonian and Newtonian fluids. The graph is plotted between torque and speed, and the relationship between them is explained by an equation $T=g+h \mathrm{~N}$. The constant " $g$ " is the intercept on $x$-axis, and " $h$ " is the slope. This is similar to the equation of the Bingham model, $t=\tau_{0}+\mu \dot{\gamma}$. When comparing both equations, it is found that " $g$ " and " $h$ " are the measure of " $\tau_{0}$ " and " $\mu$," respectively, where $\tau_{0}$ is the yield stress and $\mu$ is the plastic viscosity $[21,24,26]$. The calibration constant $K$ for various speeds is finally determined using the relation, $\eta$ app $=\left(\tau_{0} / K \times N\right)+\mu$ where $\eta$ app is the apparent viscosity of the non-Newtonian fluid, which is equal to $35.11 \mathrm{cSt}$. The constant $G$ is determined using the Newtonian fluid by formula $G=(T / N * \eta)$. Power consumption $P 1$ and $P 2$ are shown in Figure 5. The graph plotted between torque and speed for the non-Newtonian fluid is obtained to determine the value " $g$ " and " $h$," which give the value $\tau_{0}=73.793$ and $\mu=-27.884$, as shown in Figure 6 . The calibration constant $K$ and $G$ obtained for various speeds are shown in Table $4[21,24]$.

4.5. Testing with the Coaxial Cylinder Viscometer. Concrete is input into the coaxial viscometer drum to determine the yield stress. The hook arrangement controls the speed and can adjust for various speeds [36]. The electrical power consumption $P_{1}$ and $P_{2}$ are calculated. The difference between these two powers $\left(P_{1}-P_{2}\right)=P$, divided by speed, $N$, gives the value of torque, and $T$, in an arbitrary unit. The calculated data is recorded, and the graph is plotted against torque vs. speed. The best fit is obtained by linear regression $[21,22]$. The linear curve is represented by the power equation, $T=g+h N$ [36-38]. " $g$ " and " $h$ " are obtained from the graph. The yield stress of the concrete is obtained from the constant $K$ and $G$ by the formula $\tau_{0}=(K / G) g$ and $\mu=(1 /$ $G) h[21]$. The concrete mix whose slump ranges from 20 to $300 \mathrm{~mm}$ is used in this coaxial viscometer. It shows a good result for normal grade concrete, self-compacting concrete, and high-performance concrete, whose size of aggregate ranges from $12 \mathrm{~mm}$ to $25 \mathrm{~mm}$ [22]. Concrete for various

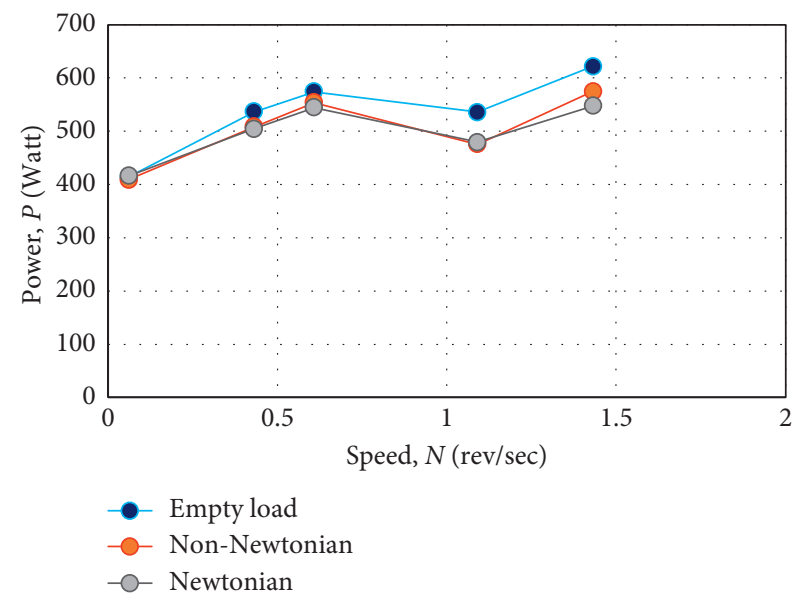

FIGURE 5: Power consumption for empty load, non-Newtonian fluid, and Newtonian fluid.

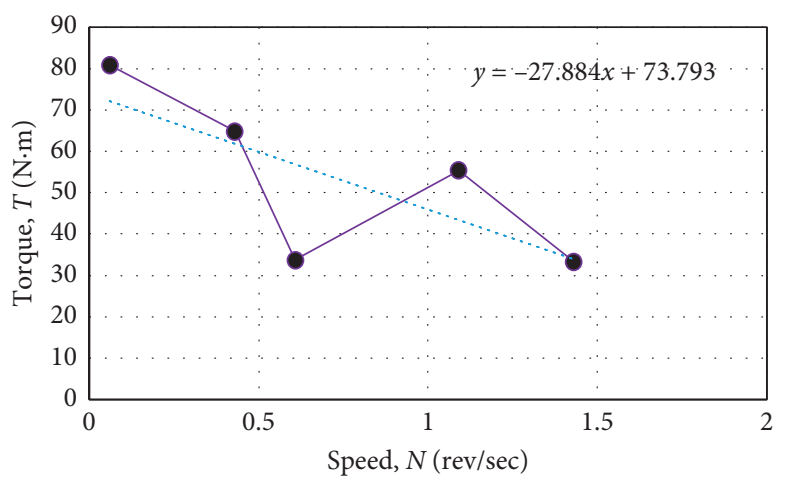

Figure 6: Torque vs. speed for the non-Newtonian fluid to determine " $g$ " and " $h$ " which are equal to " $\tau_{0}$ " and " $\mu$." Hence, $\tau_{0}=73.793$ and $\mu=-27.884$. The apparent viscosity is calculated by the formula, $\eta$ app $=\left(\tau_{0} / K \times N\right)+\mu, 35.11=73.79 /(K \times N)=-27.88$, $35.11+27.88=73.79 /(K \times N), 62.99=73.79 /(K \times N)$, and $K=73.79 /$ $(62.99 \times N)$.

TABle 4: Determination of the calibration constant $K$ and $G$ for the various speeds.

\begin{tabular}{lccccc}
\hline S. no. & Speed & Torque & $\eta$ & $K$ & $G=(T / N * \eta)$ \\
\hline 1 & 0.06 & 29.16 & 35.11 & 19.52 & 13.8 \\
2 & 0.43 & 74.51 & 35.11 & 2.72 & 4.9 \\
3 & 0.608 & 32.87 & 35.11 & 1.92 & 1.53 \\
4 & 1.09 & 51.27 & 35.11 & 1.07 & 1.3 \\
5 & 1.41 & 52.98 & 35.11 & 0.82 & 1.07 \\
\hline
\end{tabular}




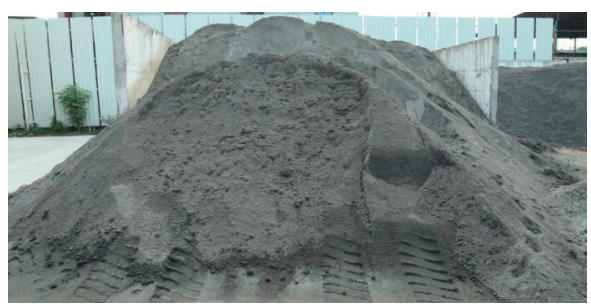

(a)

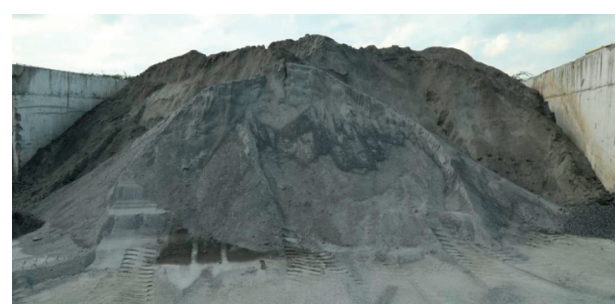

(b)

Figure 7: (a) $M$-sand in the RMC plant. (b) $C$-sand in the RMC plant.

TABLE 5: Chemical composition of the binding material in $\%$ of the composition.

\begin{tabular}{lccccccccccccc}
\hline Components & $\mathrm{SiO}_{2}$ & $\mathrm{Al}_{2} \mathrm{O}_{3}$ & $\mathrm{CaO}$ & $\mathrm{MgO}$ & $\mathrm{Fe}_{2} \mathrm{O}_{3}$ & $\mathrm{SO}_{3}$ & $\mathrm{~S}$ & $\mathrm{Cl}$ & $\mathrm{K}_{2} \mathrm{O}$ & $\mathrm{Na}_{2} \mathrm{O}$ & $\mathrm{TiO}_{2}$ & $\mathrm{Mn}_{2} \mathrm{O}_{3}$ \\
\hline Cement & 23.2 & 6.3 & 63.5 & 1.5 & 3.1 & 1.7 & - & 0.02 & 0.2 & 0.35 & - & - \\
Fly ash & 55.9 & 22.5 & 4.1 & 1.6 & 8.8 & 1.5 & 0.4 & 0.005 & 2.7 & 1.09 & 0.78 & 0.17 \\
GGBS & 33.5 & 13.7 & 39.4 & 5.9 & 6.1 & 0.5 & 0.32 & 0.005 & - & - & 0.3 & 0.24 \\
\hline
\end{tabular}

grades is designed, and the required quantity of cement, fine aggregate, coarse aggregate, and water are mixed with the help of a drum-type mixer uniformly. The thoroughly mixed concrete is input into the coaxial cylinder which is fitted with an $H$-type impeller. The quantity of the concrete is taken in such a way that the impeller is immersed in concrete. Concrete is allowed to settle for a few seconds before taking the initial reading.

\section{Composition of the Concrete Ingredients}

The OPC 53 grade cement conforming to IS 269-2015 (Indian Standard) is used for concrete manufacturing. Locally available coarse aggregate, $12 \mathrm{~mm}, 20 \mathrm{~mm}$ size, and fine aggregate, $C$-sand (crusher sand), and $M$-sand (manufactured sand) conforming to IS 383-2016 are used. Fly ash conforming to IS 3812-2003, which was obtained from Ennore Thermal Power Plant in India, is used as a mineral admixture. GGBS, conforming to IS 16714:2018, is used as another mineral admixture. Polycarboxylate ether is used as a chemical admixture, as shown in Figures 7(a) and 7(b). The chemical compositions of binding materials are mentioned in Table 5. The physical properties of the binding material, aggregate, and chemical admixture are mentioned in Tables 6-8. In this study, three grades M25, M30, and M40 concrete mix were tested. Concrete is manufactured in the ready-mix concrete plant. Some quantity of concrete is taken from the manufacturing unit to measure the yield stress. The entire test is carried out in a ready-mix concrete plant. The freshly prepared concrete is immediately collected from the outlet of the mixer machine for testing before it is discharged into the truck. The slump test is also carried out to check the rheological behavior of concrete. The mix compositions are shown in Table 9.

\section{Determination of the Rheological Parameter for Concrete}

The coaxial cylinder viscometer is now filled with concrete which is collected from the RMC mixer outlet before
TABLE 6: Physical properties of the binding material.

\begin{tabular}{lccc}
\hline Properties & Cement & $\begin{array}{r}\text { Fly } \\
\text { ash }\end{array}$ & GGBS \\
\hline Specific gravity & 3.1 & 2.5 & 2.7 \\
Specific surface area (Blaine's method) & 330 & 450 & 390 \\
$\mathrm{~m}^{2} / \mathrm{kg}$ & 28 & 240 & 80 \\
Initial setting time $(\mathrm{min})$ & 450 & 600 & 570 \\
Final setting time $(\mathrm{min})$ & $28 \%$ & - & - \\
Normal consistency & & & \\
\hline
\end{tabular}

TABLE 7: Properties of aggregates.

\begin{tabular}{lcccc}
\hline Properties & (C-sand) & (M-sand) & $\begin{array}{c}\text { Gravel 1 } \\
(12 \mathrm{~mm})\end{array}$ & $\begin{array}{c}\text { Gravel 2 } \\
(20 \mathrm{~mm})\end{array}$ \\
\hline $\begin{array}{l}\text { Specific gravity } \\
\begin{array}{l}\text { Water } \\
\text { absorption }\end{array}\end{array}$ & 2.6 & 2.73 & 2.67 & 2.6 \\
$\begin{array}{l}\text { Fineness } \\
\text { modulus }\end{array}$ & 3.9 & 1.5 & 0.9 & 1 \\
\hline
\end{tabular}

TABle 8: Properties of the chemical admixture.

\begin{tabular}{|c|c|c|}
\hline Parameter & PCE & SNF \\
\hline Appearance & $\begin{array}{c}\text { Reddish-brown } \\
\text { liquid }\end{array}$ & Reddish-brown liquid \\
\hline Chemical name & $\begin{array}{l}\text { Polycarboxylic } \\
\text { ether }\end{array}$ & $\begin{array}{l}\text { Sulphonated naphthalene } \\
\text { formaldehyde }\end{array}$ \\
\hline Type & $\begin{array}{c}\text { Retarding } \\
\text { superplasticizer }\end{array}$ & Retarding superplasticizer \\
\hline $\mathrm{pH}$ & 6 & 6 \\
\hline Relative density & 1.11 & 1.11 \\
\hline $\begin{array}{l}\text { Chloride } \\
\text { content (\%) }\end{array}$ & 0.2 & 0.2 \\
\hline
\end{tabular}

discharging into the truck. Power consumption for the various grade, $w / p$ ratio, and speeds are shown in Figures $8-10$. The torque obtained is plotted against the 
TABLE 9: Composition of the concrete ingredients.

\begin{tabular}{lccccccccc}
\hline Components & S11 & S12 & S13 & S21 & S22 & S23 & S31 & S32 & S33 \\
\hline Grade & M25 & M25 & M25 & M30 & M30 & M30 & M40 & M40 & M40 \\
Cement & 200 & 200 & 330 & 200 & 260 & 370 & 360 & 280 & 410 \\
Fly ash & 0 & 50 & 70 & 50 & 0 & 72 & 100 & 0 & 80 \\
GGBS & 150 & 150 & 0 & 170 & 140 & 0 & 0 & 200 & 0 \\
Sand 1 & 458 & 438 & 432 & 444 & 382 & 320 & 349 & 350 & 363 \\
Sand 2 & 305 & 292 & 322 & 290 & 382 & 339 & 349 & 350 & 363 \\
Gravel 1 & 517 & 505 & 515 & 510 & 734 & 415 & 461 & 483 \\
Gravel 2 & 665 & 649 & 661 & 652 & 400 & 580 & 644 & 647 \\
Superplasticizer & 2.8 & 2.4 & 2.6 & 2.52 & 2.8 & 2.4 & 2.76 & 2.88 \\
Water & 165 & 165 & 167 & 165 & 165 & 165 & 168 & 154 \\
w/c ratio & 0.47 & 0.41 & 0.41 & 0.39 & 0.41 & 0.37 & 0.36 & 0.34 \\
Density & 2463 & 2451 & 2500 & 2484 & 2466 & 2263 & 2434 & 2478 \\
Production & & & & & & & 0.33 \\
Quantity & 6 & 6 & 6 & 6 & 6 & 5 & 5 & 2463 \\
Batch size & 1 & 1 & 1 & 1 & 1 & 1 & 1 & 6 \\
Bulk density & 15000 & 14862 & 14778 & 14904 & 14796 & 13578 & 14868 & 14508 \\
\hline
\end{tabular}

Materials in $\mathrm{kg}$, density in $\mathrm{kg} \cdot \mathrm{m}^{3}$, quantity in $\mathrm{m}^{3}$.

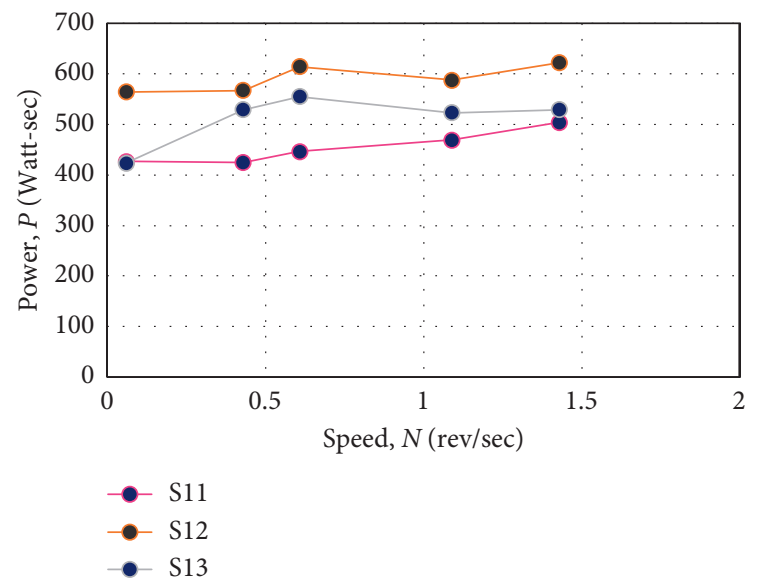

Figure 8: Power consumption for M25 grade concrete.

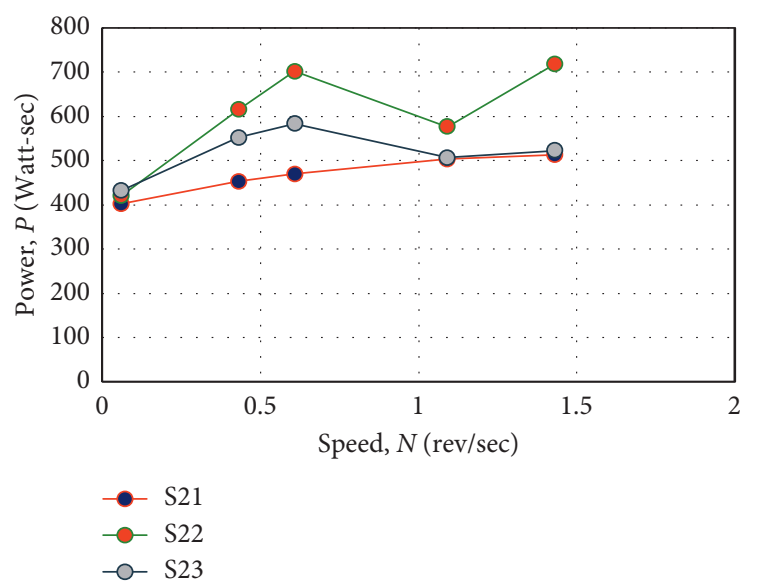

Figure 9: Power consumption for M30 grade concrete.

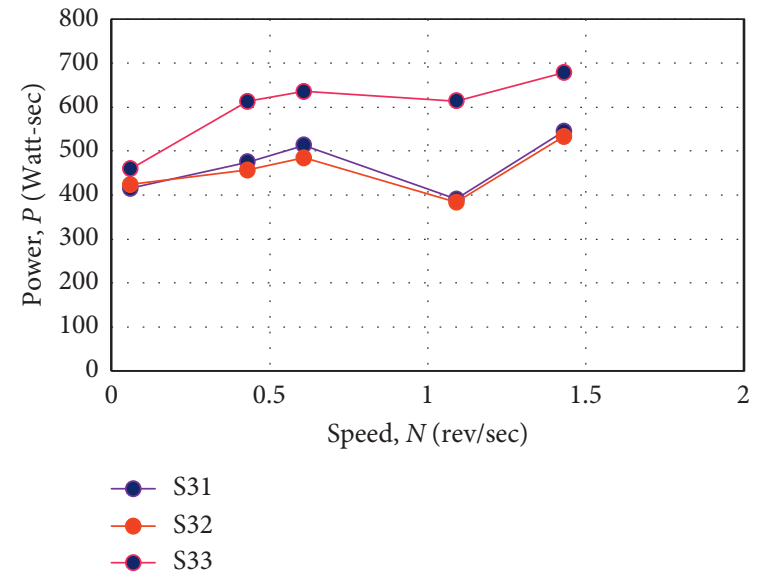

Figure 10: Power consumption for M40 grade concrete.

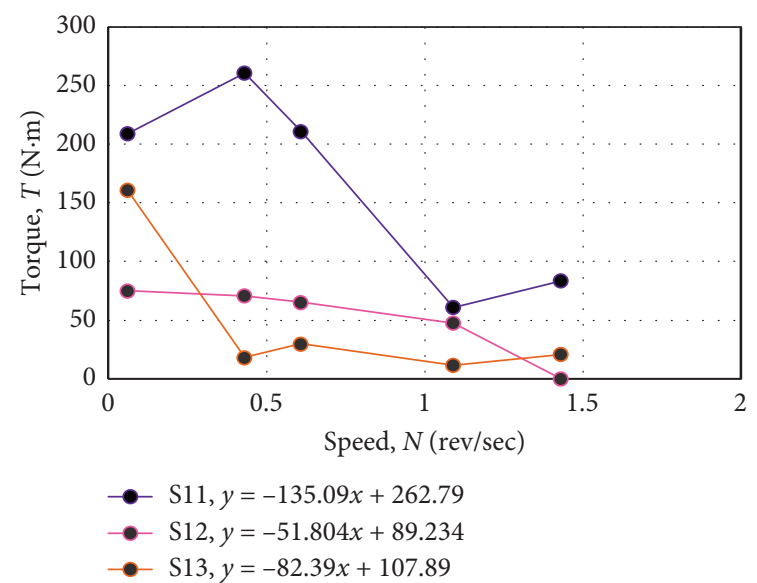

Figure 11: Torque for M25 grade concrete. 


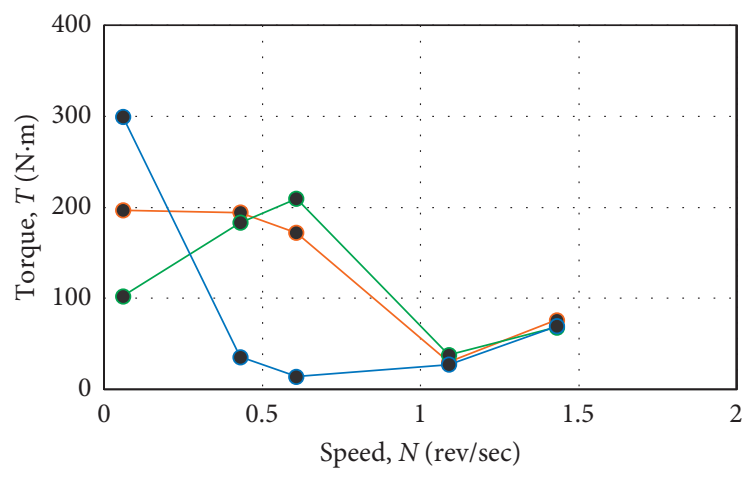

- S $21, y=-121.49 x+221.71$

- $\mathrm{S} 22, y=-71.552 x+171.99$

-- S23, $y=-129.38 x+182.68$

Figure 12: Torque for M30 grade concrete.

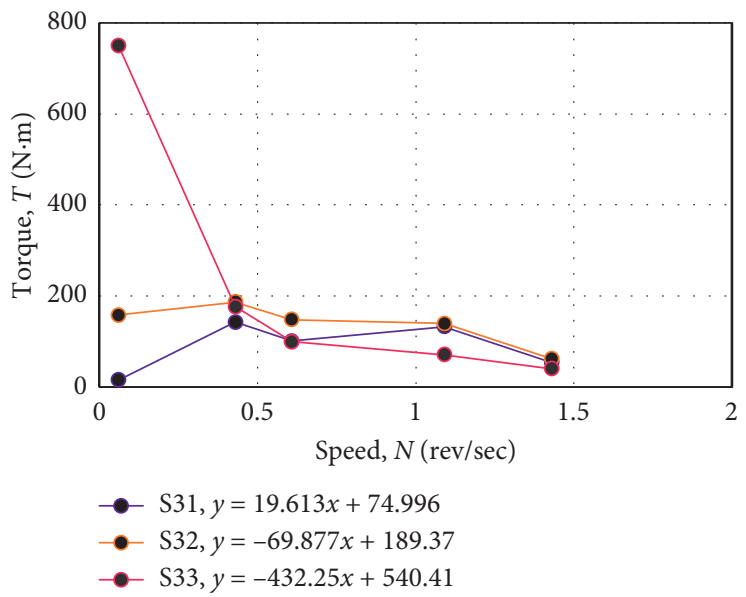

FIgURE 13: Torque for M40 grade concrete.

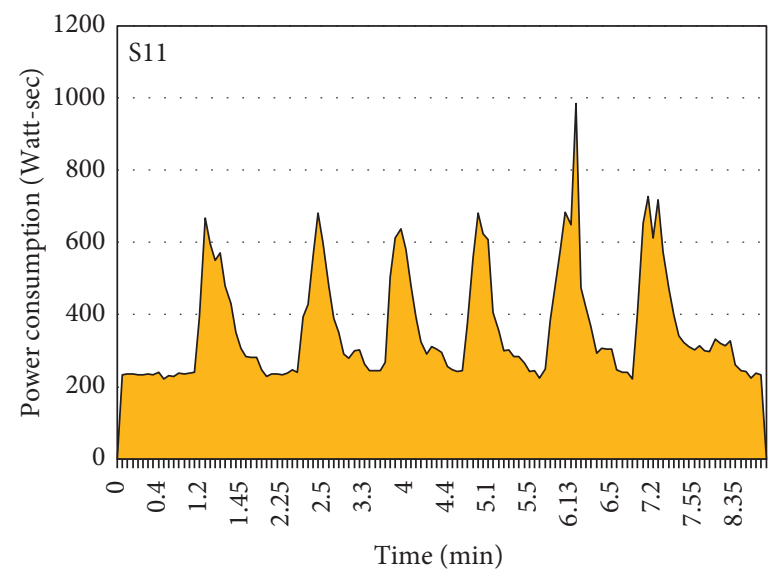

(a)

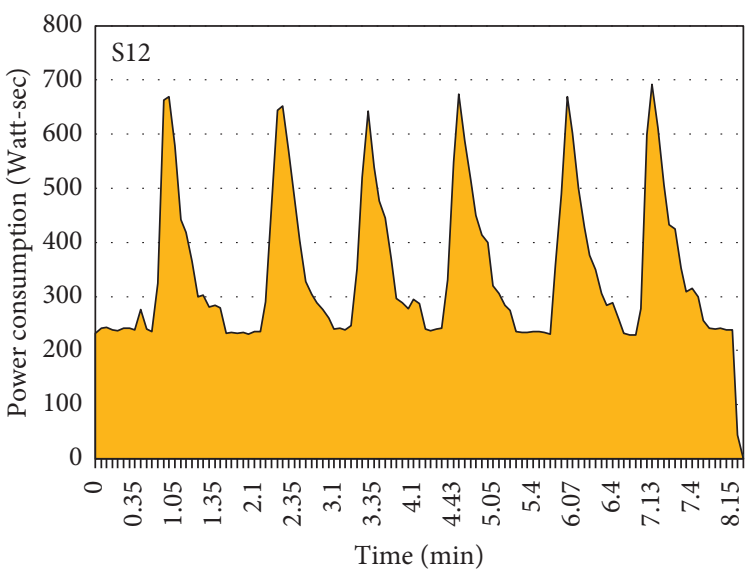

(b)

FIgUre 14: Continued. 


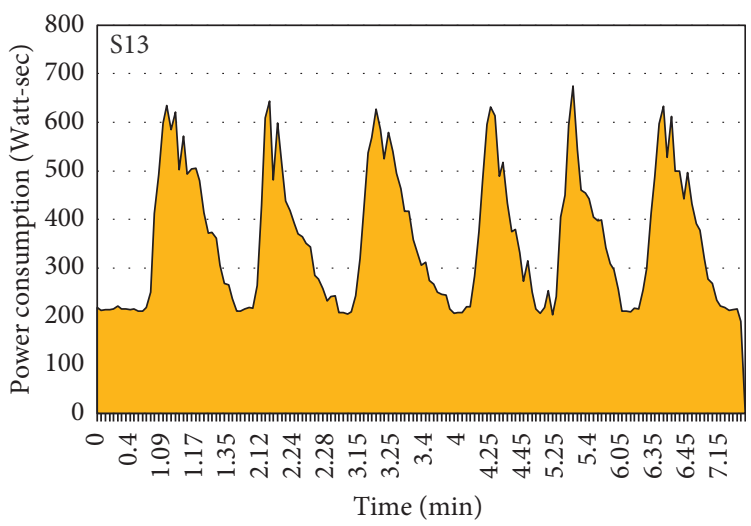

(c)

FIgURE 14: Power consumption curve for M25 grade concrete.

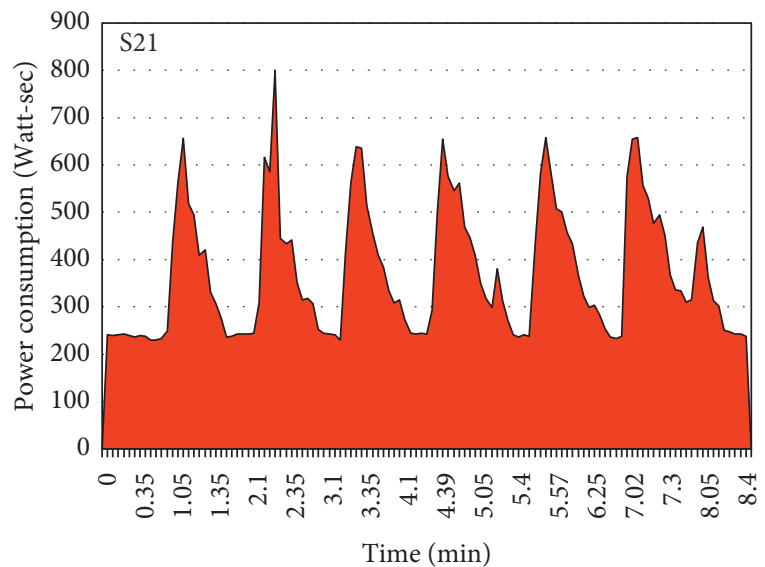

(a)

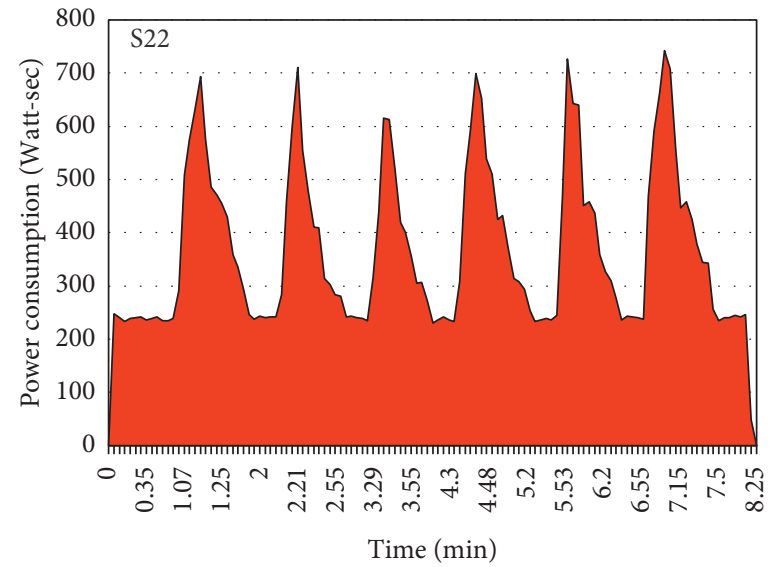

(b)

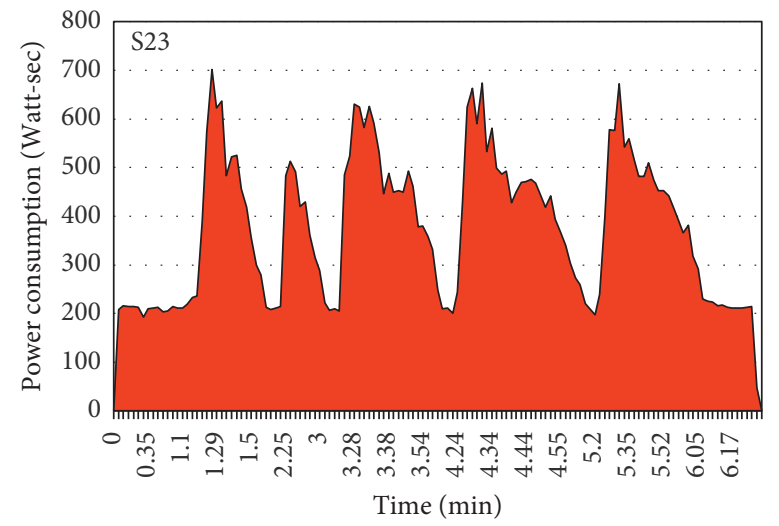

(c)

FIGURE 15: Power consumption curve for M30 grade concrete. 


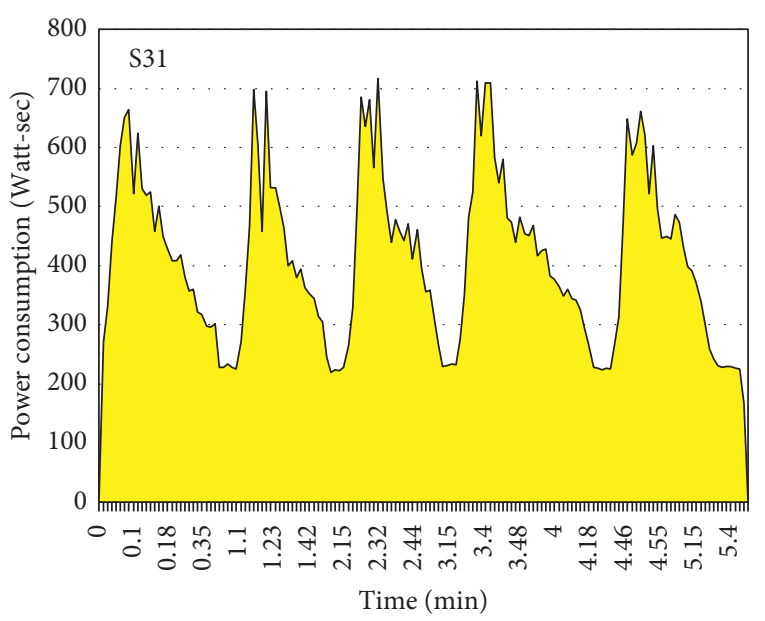

(a)

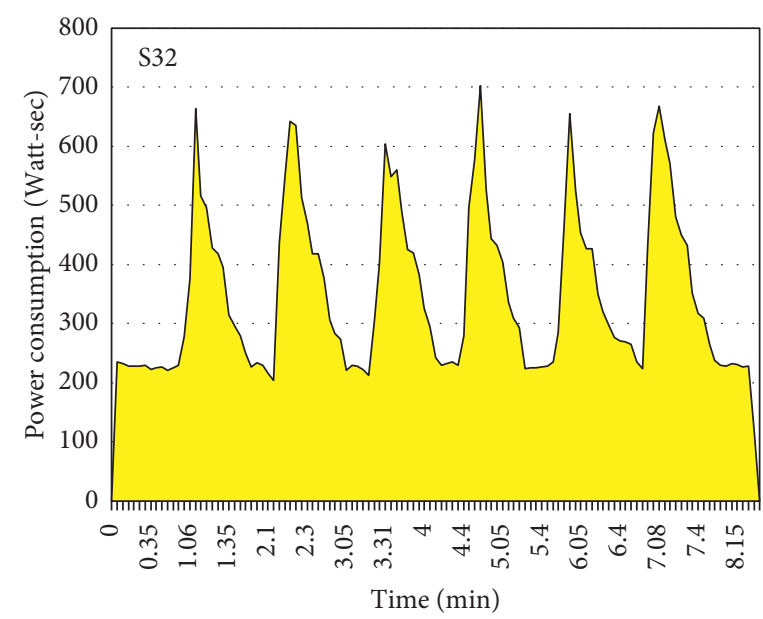

(b)

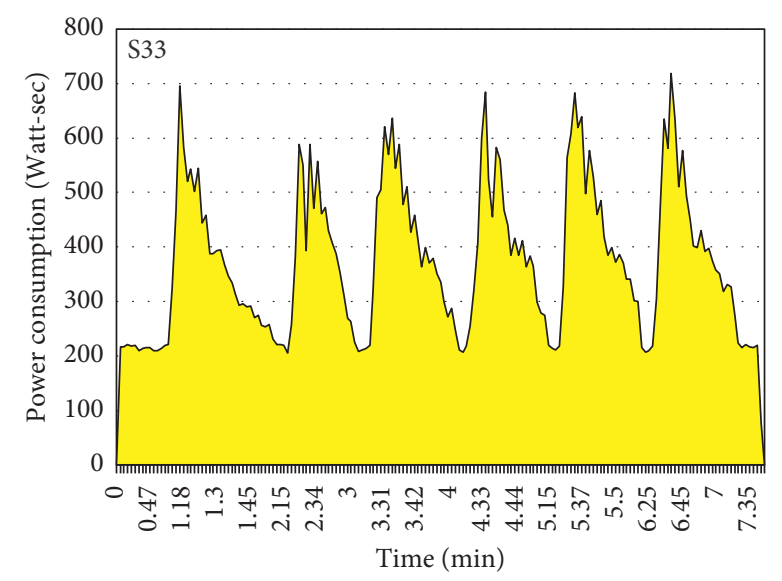

(c)

Figure 16: Power consumption curve for M40 grade concrete.

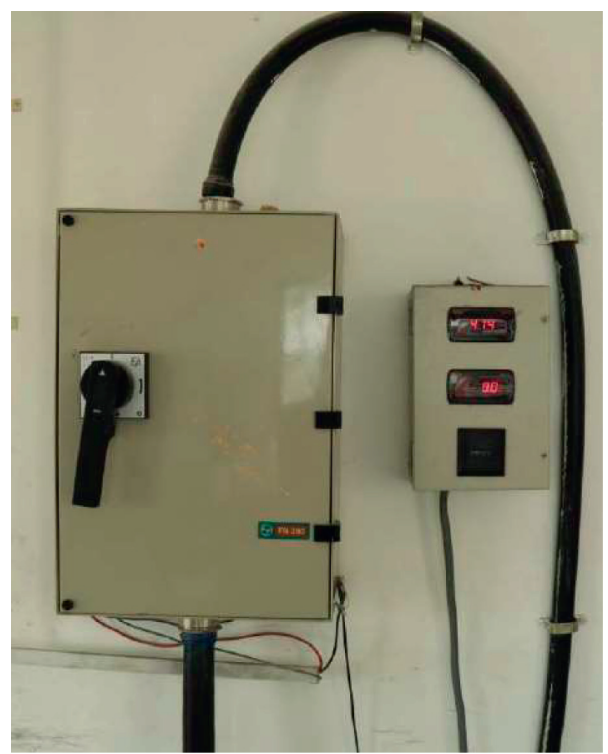

FIgURE 17: Wattmeter. 
TABLE 10: Yield stress for various rev/sec.

\begin{tabular}{lccccc}
\hline Mix & 0.06 & 0.43 & 0.608 & 1.09 & 1.43 \\
\hline S11 & 371.71 & 144.69 & 327.63 & 209.84 & 71.25 \\
S12 & 126.22 & 49.13 & 111.25 & 86.15 & 69.03 \\
S13 & 59.41 & 134.51 & 177.04 & 83.46 \\
S21 & 122.08 & 276.42 & 137.34 & 171.51 \\
S22 & 152.61 & 94.70 & 214.43 & 145.87 & 133.05 \\
S23 & 13.61 & 41.29 & 227.76 & 59.88 & 141.49 \\
S31 & 241.28 & 104.27 & 93.50 & 151.21 & 58.02 \\
S32 & 258.4 & 236.10 & 431.52 & 146.49 \\
S33 & 106.08 & 297.55 & 673.76 & 418.05 \\
\hline
\end{tabular}

TABle 11: Power consumption, relative yield stress, and slump for M25, M30, and M40 grade concrete.

\begin{tabular}{lccccccccc}
\hline Components & M11 & M12 & M13 & M21 & M22 & M23 & M31 & M32 & M33 \\
\hline Power consumption (Watt-sec) & 349.15 & 350.85 & 355.32 & 368.27 & 358.27 & 378.04 & 367.47 & 344.1 & 410.062 \\
Relative yield stress $\left(\mathrm{N} / \mathrm{mm}^{2}\right)$ & 317.09 & 105.4 & 127.92 & 267.57 & 182.7 & 220 & 90.506 & 161.36 & 652.19 \\
Slump (mm) & 190 & 150 & 150 & 170 & 180 & 180 & 150 & 180 & 200 \\
\hline
\end{tabular}

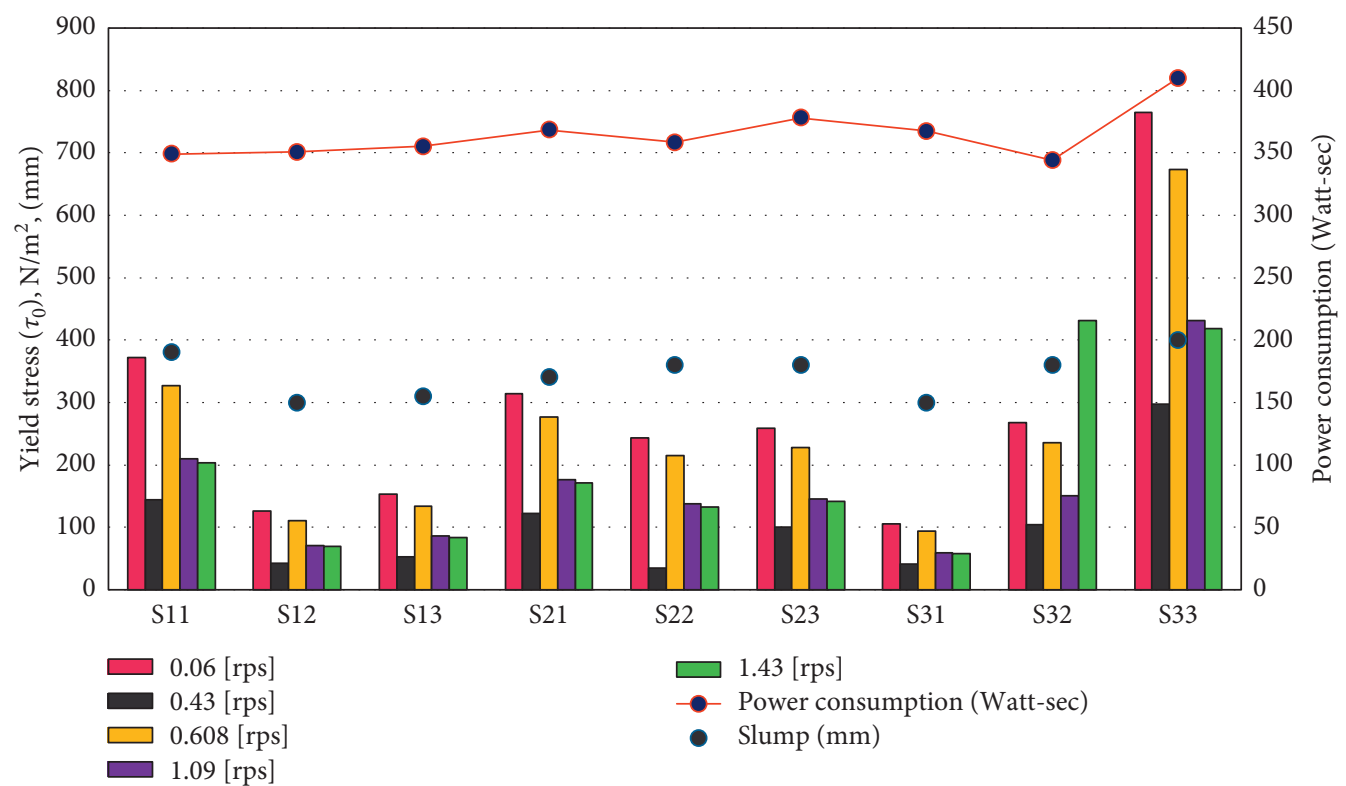

FIGURE 18: Yield stress for the different mix for various rev/sec and corresponding slump value versus power consumption.

speed, as shown in Figures 11-13. From the graph, " $g$ " and " $h$ " are obtained and then used to calculate $\tau_{0}$ and $\mu$.

\section{Energy Consumption Curve of M25, M30, and M40}

The energy consumption curve of all the mix is shown in Figures 14-16. The wattmeter reading during the mixing process is recorded, as shown in Figure 17. Later, voltage and current are noted down to obtain the power consumption curve. The curve is plotted between time and power consumption. The total power consumed during mixing was also calculated.

\section{Result}

(i) The yield stress measured in the coaxial viscometer for M25, M30, and M40 for various rev/sec is mentioned in Table 10. The corresponding relative stress and power consumption are shown in Table 11.

(ii) It is evident from Figure 18 that an increase in the slump value will increase the yield stress. The 


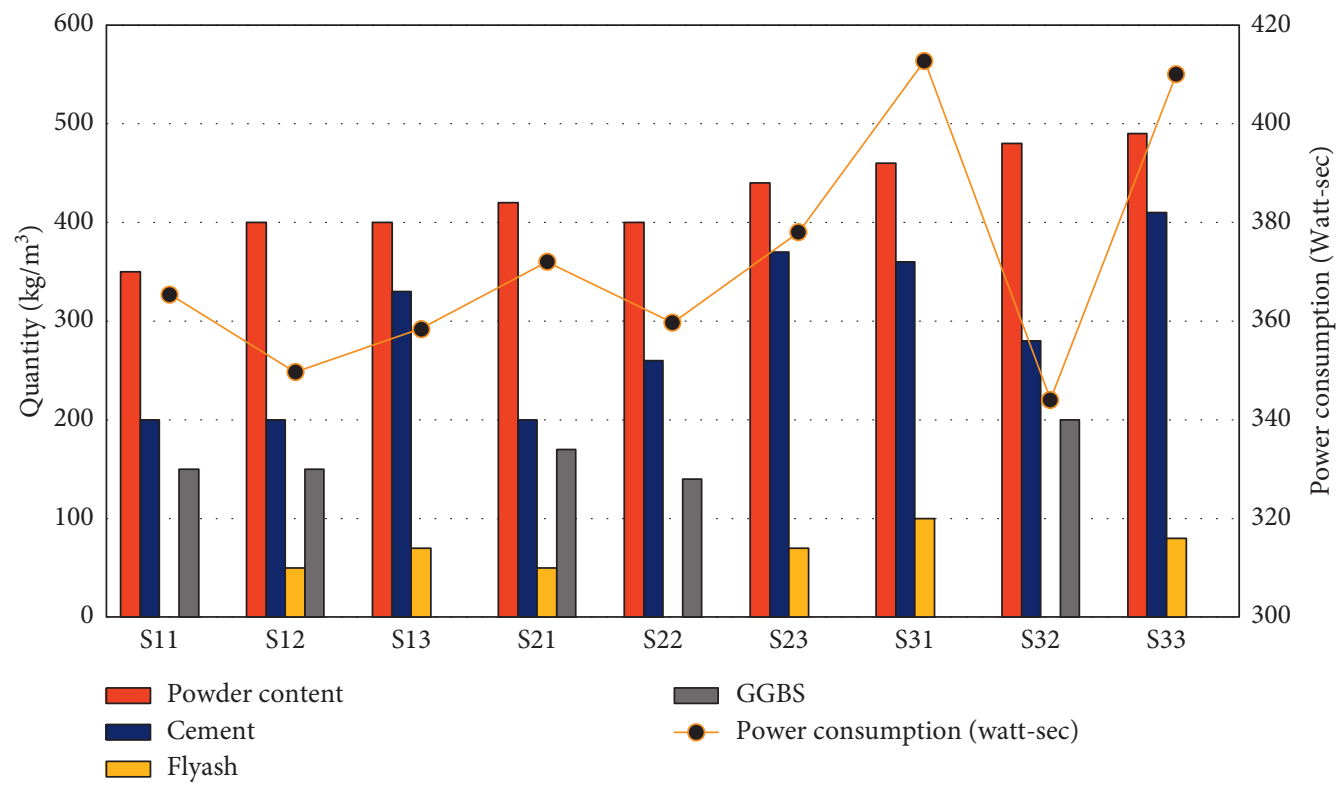

FIGURE 19: Power consumption is related with total powder content, cement content, fly ash, and GGBS in $\mathrm{kg} / \mathrm{m}^{3}$.

slump value is very high for the mix S33, S23, and S21 which gives high yield stress and high power consumption during the mixing of concrete.

(iii) From Figure 18, it is observed that yield stress is maximum at minimum rev/ $/ \mathrm{sec}$, i.e., $0.06 \mathrm{rev} / \mathrm{sec}$, and it gives peak value for M40 grade concrete, i.e., S33 mix at minimum rev/sec.

(iv) For all of the mixes, the maximum yield stress is obtained at minimum rev/ $\mathrm{sec}$, i.e., at $0.06 \mathrm{rev} / \mathrm{sec}$, and gives minimum yield stress at $1.09 \mathrm{rev} / \mathrm{sec}$.

(v) It is understood from Figure 18 that further scrutinization is required for power consumption. The increase in power consumption may depend on some other factor, such as powder content (cement + fly ash + GGBS), admixture content, and cement content. Hence, from Figure 19, the relation between power consumption and other factors such as total powder content and amount of cement, fly ash, and GGBS can be found.

(vi) From Figure 19, it is observed that power consumption for a M40 grade concrete, i.e., for mixes S31 and S33, consumes more power during mixing of concrete in RMC production which is due to the presence of fly ash and absence of GGBS. The S32 mix consumes a minimum power due to the presence of GGBS and the absence of fly ash. The maximum and the minimum power consumptions are due to the absence and the presence of GGBS, respectively. Oppositely, the presence of fly ash consumes more power during mixing, and the absence of fly ash consumes less power.

(vii) In M30 grade concrete, mixes S21 and S22 consume a minimum power in the presence of GGBS content and with the absence of fly ash. The S23 mix consumes maximum power in the absence of GGBS and with the presence of fly ash.

(viii) In M25 grade concrete, the S13 mix consumes more power than mixes $\mathrm{S} 11$ and $\mathrm{S} 12$ in the presence of fly ash. The S12 mix consumes minimum power in a higher content of GGBS and fewer fly ash. The S11 mix consumes maximum power during mixing even in the presence of GGBS. The reason behind this may be due to the presence of minimum powder content compared to all other mixes.

(ix) Overall results indicate that the presence of the GGBS consumes less power consumption and fly ash consumes more power during the mixing process.

\section{Conclusion and Discussion}

Concrete is an exceptional material, which cannot be compared with any other Newtonian and non-Newtonian material. Concrete is highly sensitive since its yield stress measured within fifteen minutes will show different values after concrete starts its initial setting. Therefore, there is a random variation in the yield stress and relative yield stress for different rev/sec in this study. The power consumption during mixing of the self-compacting concrete in the RMC plant varies mainly due to different admixtures added into the concrete mix. The mineral admixtures used in the concrete have different physical and chemical properties. As a consequence, all materials do not behave in the same manner. Identifying the material that minimizes the power consumption and using it in the manufacture of concrete reduces the manufacturing process's energy. Optimization of energy in all the fields is the ultimate goal to protect our natural resources. From the results above, it is concluded 
that power consumption does not directly have an impact on the yield stress of concrete. The ingredients added to the concrete cause an increase or decrease in power consumption, and these ingredients are the cause for an increase or decrease in the yield stress. The power consumption varies for every mix depending on the admixtures, such as fly ash and GGBS, added. The addition of GGBS and fly ash is the leading cause of the increase in yield stress. Power consumption and yield stress increase or decrease due to the mineral admixtures added into the concrete. It also depends on the total amount of powder content and characteristics of the ingredient added into the concrete. The texture of the ingredients is another factor that causes inner abrasion on the surface of the drum. Abrasion and interparticle collision of the mineral admixtures with aggregate is another factor that causes a rise in power consumption. The mixing drum finds it difficult to rotate since the hard particle resists the rotation, and in order to balance the torque, the drum consumes greater power to rotate. This is the main reason for the difference in power consumption when using different admixtures. The flowability of concrete is another factor for an increase or decrease in the yield stress and power consumption. That is, an increase in the slump value leads to a considerable increase in the yield stress and power consumption.

\section{Glossary}

RMC: Ready-mix concrete

SCC: $\quad$ Self-compacting concrete

GGBS: Ground granulated blast-furnace slag

$K$ and $G$ : Calibration constant for coaxial viscometer

$\tau_{0}: \quad$ Yield stress

$\mu$ : $\quad$ Plastic viscosity

$\tau$ : $\quad$ Shear stress

$\dot{\gamma}: \quad$ Shear rate

$g: \quad$ Intercept of $x$-axis

h: $\quad$ Slope

T: $\quad$ Torque

$N: \quad$ Speed

P: $\quad$ Power

$V: \quad$ Voltage

I: $\quad$ Current

cSt: $\quad$ Centistoke

$\eta$ Viscosity.

\section{Data Availability}

The energy consumption data used to support the findings of this study have been deposited in the reference [5].

\section{Conflicts of Interest}

The authors declare that they have no conflicts of interest.

\section{References}

[1] K. Kermeli, E. Worrell, and E. Masanet, Energy Efficiency Improvement and Cost Saving Opportunities for the Concrete Industry, an Energy Star ${ }^{\circledR}$ Guide for Energy and Plant
Managers, Ernest Orlando Lawrence Berkeley National Laboratory, Berkeley, CA, USA, 2011, https://www.energystar.gov/ sites/default/files/buildings/tools/Energy_Efficieny_Improvement_ Cost_Saving_Opportunities_Concrete.pdf.

[2] J. M. Juez, R. Artoni, and B. Cazacliu, "Monitoring of concrete mixing evolution using image analysis," Powder Technology, vol. 305, pp. 477-87, 2017.

[3] D. Lowke and P. Schiessl, "Effect of mixing energy on fresh properties of SCC," in Proceeding Fourth International RILEM Symposium on Self-Compacting Concrete SCC, pp. 517-523, 2005, http://www.schleibinger.com/k2005/zusammenfassung/ mixing\%2003.pdf.

[4] P. Schießl, O. Mazanec, and D. Lowke, "SCC and UHPC-effect of mixing technology on fresh concrete properties," Advances in Construction Materials, pp. 513-522, 2007, https://link.springer.com/chapter/10.1007/978-3-54072448-3_52.

[5] B. Cazacliu, "In-mixer measurements for describing mixture evolution during concrete mixing," Chemical Engineering Research and Design, vol. 86, no. 12, pp. 1423-1433, 2008.

[6] B. Daumann and H. Nirschl, "Assessment of the mixing efficiency of solid mixtures by means of image analysis," Powder Technology, vol. 182, no. 3, pp. 415-423, 2008.

[7] J. Dils, G. De Schutter, and V. Boel, "Influence of mixing procedure and mixer type on fresh and hardened properties of concrete: a review," Materials and Structures, vol. 45, no. 11, pp. 1673-1683, 2012.

[8] D. Chopin, F. Larrard, and B. Cazacliu, "Why do HPC and SCC require a longer mixing time?" Cement and Concrete Research, vol. 34, no. 12, pp. 2237-2243, 2004.

[9] O. de Larrard, D. Lowke, and P. Schießl, "Mixing of high performance concrete: effect of concrete composition and mixing intensity on mixing time," Materials and Structures, vol. 43, no. 3, pp. 357-365, 2010.

[10] H. Beitzel, "Optimisation of the mixing process for producing self-compacting high-performance concrete," Design, Production and Placement of Self-Consolidating Concrete, vol. 1, pp. 175-183, 2010.

[11] R. F. Aziz, "Statistical model for predicting and improving ready mixed concrete batch plants' performance ratio under different influences," Alexandria Engineering Journal, vol. 57, no. 3, pp. 1797-1809, 2018.

[12] B. Cazacliu and J. Legrand, "Characterization of the granularto-fluid state process during mixing by power evolution in a planetary concrete mixer," Chemical Engineering Science, vol. 63, no. 18, pp. 4617-4630, 2008.

[13] H.-T. Ngo, E.-H. Kadri, A. Kaci, T.-T. Ngo, A. Trudel, and S. Lecrux, "Advanced online water Content measurement for self-compacting concrete production in ready-mixed concrete Plants," Construction and Building Materials, vol. 112, pp. 570-580, 2016.

[14] R. Collet, D. Oulahna, A. De Ryck, P. H. Jezequel, and M. Martin, "Mixing of a wet granular medium: influence of the liquid addition method," Powder Technology, vol. 208, no. 2, pp. 367-371, 2011.

[15] B. Daumann, H. Anlauf, and H. Nirschl, "Determination of the energy consumption during the production of various concrete recipes," Cement and Concrete Research, vol. 39, no. 7, pp. 590-599, 2009.

[16] B. Cazacliu and N. Roquet, "Concrete mixing kinetics by means of power measurement," Cement and Concrete Research, vol. 39, no. 3, pp. 182-194, 2009.

[17] R. G. Pileggi, A. R. Studart, V. C. Pandolfelli, and J. Gallo, "How mixing affects the rheology of refractory castables, part 
2," American Ceramic Society Bulletin, vol. 80, pp. 38-42, 2001.

[18] B. Cazacliu, "Monitoring of concrete mixing evolution using image analysis," Powder Technology, vol. 305, pp. 477-487, 2017.

[19] M. Yang and H. M. Jennings, "Influences of mixing methods on the microstructure and rheological behavior of cement paste," Advanced Cement Based Materials, vol. 2, no. 2, pp. 70-78, 1995.

[20] L. Prasittisopin and D. Trejo, "Effects of mixing variables on hardened characteristics of Portland cement mortars," ACI Materials Journal, vol. 112, pp. 399-408, 2015.

[21] G. H. Tatersall and P. F. Banfill, The Rheology of Fresh Concrete, Pitman, London, UK, 1983, https://scholar.google. com/scholar_lookup?title=The\%20Rheology\%20of\%20Fresh \%20Concrete\&author=G.H.\%20Tattersall\&publication_year=1983.

[22] P. L. J. Domone, X. Yongmo, and P. F. G. Banfill, "Developments of the two-point workability test for high-performance concrete," Magazine of Concrete Research, vol. 51, no. 3, pp. 171-179, 1999.

[23] P. Banfill, D. Beaupré, F. Chapdelaine et al., "Comparison of concrete rheometers, international tests at LCPC (Nantes, France)," NISTIR 6819, https://tsapps.nist.gov/publication/ get_pdf.cfm?pub_id=860380, October, 2000.

[24] P. F. G. Banfill, G. Starrs, G. Derruau, W. J. McCarter, and T. M. Chrisp, "Rheology of low carbon fibre content reinforced cement mortar," Cement and Concrete Composites, vol. 28, no. 9, pp. 773-780, 2006.

[25] D. Feys, G. De Schutter, K. H. Khayat, and R. Verhoeven, "Changes in rheology of self-consolidating concrete induced by pumping," Materials and Structures, vol. 49, no. 11, pp. 4657-4677, 2016.

[26] F. J. Adewale, A. P. Lucky, P. Abioye, A. P. Oluwabunmi, F. Elehinafe, and E. F. Boluwaji, "Selecting the most appropriate model for rheological characterization of synthetic based drilling mud," IJAER, vol. 18, pp. 7614-7629, 2017.

[27] D. Feys, R. Cepuritis, S. Jacobsen, K. Lesage, E. Secrieru, and A. Yahia, "Measuring rheological properties of cement pastes: most common techniques, procedures and challenges," RILEM Technical Letters, vol. 2, pp. 129-135, 2017.

[28] E. P. Koehler and D. W. Fowler, Summary of Workability TestMethod' Research Report, ICAR, Austin, TX, USA, 2003, https://repositories.lib.utexas.edu/bitstream/handle/2152/ 35335/105-1_completed.pdf? sequence $=2$.

[29] A. Yahia and K. H. Khayat, "Modification of the concrete rheometer to determine rheological parameters of self-consolidating concrete-vane device," in Proceedings of the 2 nd International RILIM Symposium on Advances in Concrete through Science Engineering, Quebec City, Canada, September 2006.

[30] X. Kong, Y. Zhang, and S. Hou, "Study on the rheological properties of Portland cement pastes with polycarboxylate superplasticizers," Rheologica Acta, vol. 52, no. 7, pp. 707-718, 2013.

[31] O. H. Wallevik, "The rheology of fresh concrete and its application on concrete with and without silica fume," Dr. thesis, NTH, Trondheim, Norway, 1990.

[32] Z. Toutou and N. Roussel, "Multi scale experimental study of concrete rheology: from water scale to gravel scale," Materials and Structures, vol. 39, no. 2, pp. 189-199, 2006.

[33] C. Hu and F. de Larrard, "The rheology of fresh high-performance concrete," Cement and Concrete Research, vol. 26, no. 2, pp. 283-294, 1996.
[34] P. Coussot, "Rhéologie des boues et laves torrentielles-étude de dispersions et suspensions concentrées," Ph.D. thesis, Institute National Polytechnique de Grenoble, Grenoble, France, 1993, in French, http://www.theses.fr/1992INPG0086.

[35] G. H. Tattersall and S. J. Bloomer, "Further development of the two point test for workability and extension of its test for workability and extension of its range," Magazine of Concrete Research, vol. 31, pp. 242-245, 1979.

[36] P. F. G. Banfill, "A viscometric study of cement pastes containing superplasticizers with a note on experimental techniques," Magazine of Concrete Research, vol. 33, no. 114, pp. 37-47, 1981.

[37] J. H. Kim, N. Noemi, and S. P. Shah, "Effect of powder materials on the rheology and formwork pressure of selfconsolidating concrete," Cement and Concrete Composites, vol. 34, no. 6, pp. 746-753, 2012.

[38] D. Feys, K. H. Khayat, and R. Khatib, "How do concrete rheology, tribology, flow rate and pipe radius influence pumping pressure?" Cement and Concrete Composites, vol. 66, pp. $38-46,2016$. 